\title{
Aggregation and thermal properties of nanostructured montmorillonite covered with mixed adsorption layers of cationic polyacrylamide and hazardous lead(II) ions
}

\author{
Małgorzata Wiśniewska ${ }^{1}$. Gracja Fijałkowska $\cdot$ Katarzyna Szewczuk-Karpisz ${ }^{2} \cdot$ Dariusz Sternik $^{3}$
}

Received: 8 April 2020 / Accepted: 20 May 2020 / Published online: 27 May 2020

(C) The Author(s) 2020

\begin{abstract}
The aim of the study was to investigate the influence of nanostructured montmorillonite surface modification by the cationic polyacrylamide and the lead(II) ions on the thermal and aggregation properties of solid particles covered with mixed adsorption layers. The effects of cationic groups content in the polymeric macromolecules, the order of individual adsorbates addition, and lead(II) ions concentration were determined. Using spectrophotometry, potentiometric titration, microelectrophoresis, turbidimetry, DCS (Differential Centrifugal Sedimentation) and thermal analysis methods, the adsorption, electrokinetic, aggregation properties, as well as the thermal stability of studied montmorillonite- $\mathrm{CT} P A M-\mathrm{Pb}(\mathrm{II})$ systems were established. It was shown that applied polymeric substance (soil flocculant) causes accumulation of lead(II) ions, which are hazardous at very low concentrations. Nevertheless, the chemical nature of these interactions may limit the bioavailability of this heavy metal for plants.
\end{abstract}

Keywords Nanostructured montmorillonite $\cdot \mathrm{Pb}(\mathrm{II})$ ions immobilization $\cdot$ Cationic polyacrylamide adsorption $\cdot$ Mixed $\mathrm{PAM}-\mathrm{Pb}(\mathrm{II})$ aggregates $\cdot$ Thermal stability

\section{Introduction}

The macromolecular compound addition affects the stability and rheological properties of colloidal systems. Depending on the conditions, the polymer presence may increase or decrease the aggregates' stability. The polymer impact contributing to the suspension stability increase is described as polymeric stabilization (of steric and elecrosteric character), whereas the suspension stability reduction is also connected with the polymer flocculation. These effects are

Małgorzata Wiśniewska

wisniewska@hektor.umcs.lublin.pl

1 Department of Radiochemistry and Environmental Chemistry, Faculty of Chemistry, Institute of Chemical Sciences, Maria Curie-Sklodowska University in Lublin, M. Curie-Sklodowska Sq. 3, 20-031 Lublin, Poland

2 Institute of Agrophysics, Polish Academy of Sciences, Doświadczalna 4, 20-290 Lublin, Poland

3 Department of Physical Chemistry, Faculty of Chemistry, Institute of Chemical Sciences, Maria Curie-Sklodowska University in Lublin, M. Curie-Sklodowska Sq. 3, 20-031 Lublin, Poland strongly associated with polymer adsorption on the particle surface or the presence of non-adsorbed polymer macromolecules in the dispersing phase (Zaman et al. 2002; Pan et al. 2001). The polymer as a substance of high molecular weight shows a much greater tendency to adsorption on the solid surface than compounds of lower molecular weight. It is the result of a large macromolecules size and the presence of many active sites within them. What is more, the polymer macromolecules may assume various conformations on the solid surface. The single-chain segments can form a train, loop, and tail structures. When adsorbed polymer contains mainly long loops and tails, only a few polymer fragments have direct contact with the solid surface. Such incomplete surface coverage with macromolecules favours the formation of polymer bridges. This phenomenon is possible when the range of electrostatic interaction between the particles is smaller than the length of the polymer loops and tails. As a result of bridging flocculation, large aggregates are formed that may be easily separated from the solution. Flocculation process can also be a consequence of solid charge neutralization by polymer macromolecules (Zaman et al. 2002; Pan et al. 2001; Pelssers et al. 1990; Adachi 1995; Lu and Pelton 
2001; Elimelech et al. 1995; Renault et al. 2009; Siah Lee et al. 2014; Bajpai 1997; Agassi et al. 1995).

The phenomena of stabilization and flocculation through the polymer addition are widely used in many areas of human activity. The most important are: wastewater treatment, agriculture, chemical industry (production of paints, inks, varnishes, plastics), paper industry, production of cosmetics, food industry, ceramics, medicine and pharmacy (Zaman et al. 2002; Carter 1993; Trout 1996; Sojka et al. 2007). Macromolecular compounds are also used in soil stabilization and conditioning. Due to the high strength of interparticle bonding, the polymer may control soil erosion and degradation (Singh et al. 1996; Sojka et al. 2007; Lentz et al. 1992; Lee and Schlautma 2015). They interact mainly with the clay minerals present in the soil environment and affect their properties. As a consequence, the uptake of other compounds, i.e. nutrients, heavy metals, organic substances, also changes. In this way, the polymer presence may influence the accumulation of hazardous compounds including lead ions causing various organism diseases and disorders at very low concentrations (Pueyo et al. 2004; Kabata-Pendias 2004; McBride 2003; Chaney et al. 1998; Kumpiene et al. 2007; Van Gestel 2008). According to the Regulation of the Minister of Health in Poland on 7.12.2017 (Journal of Laws of the Republic of Poland 2017), the permissible content of lead in drinking water is $0.01 \mathrm{ppm}$, whereas in the wastewaters $0.5 \mathrm{ppm}$.

The aim of the present study was to investigate the influence of cationic flocculant presence (polyacrylamide containing quaternary amine groups-CT PAM) on the lead(II) ions adsorption on the montmorillonite surface. The experiments included the effects of cationic groups content in the polymeric macromolecules, the order of individual adsorbates addition as well as lead(II) ions concentration. The adsorption and electrokinetic properties of the examined systems were determined using spectrophotometry, potentiometric titration and microelectrophoresis methods. Moreover, thermal analysis techniques were applied to investigate the mechanism of adsorbates binding with the solid surface (Sternik et al. 2019a, b). Thermogravimetry (TG), differential thermogravimetry (DTG) and differential scanning calorimetry (DSC) coupled the analysis of gaseous products of thermal degradation using FTIR and QMS spectrometry allows not only determination of thermal degradation of solid systems modified by adsorption layers of CT PAM or/ and $\mathrm{Pb}$ (II) ions, but also the characterization of the binding mechanism of adsorbate molecules to the mineral surface groups. Additionally, the stability of examined suspensions in connection with the determination of formed aggregate sizes was studied. For this purpose turbidity measurements and differential centrifugal sedimentation (DCS) analysis were applied. As a result, the immobilization possibilities of hazardous lead(II) ions in the soil mineral/polyacrylamide flocculent system was determined. Moreover, the mechanism of $\mathrm{Pb}$ (II) ions accumulation as well as the way of their interactions with the polymer and solid surface (which affects directly the aggregation availabilities) was proposed.

\section{Experimental}

\section{Materials}

The adsorbent used in the study was 2:1 clay mineralmontmorillonite (Sigma-Aldrich). Specific surface area and its porosity were determined using the nitrogen adsorption/ desorption method (Micromeritics ASAP 2020 analyzer). The elemental composition of the aluminosilicate was determined by the XRF technique (Panalytical ED-XRF type Epsilon 3 spectrometer).The obtained results of textural properties and the elemental composition of this mineral were described in the previous paper (Wiśniewska et al. 2018).

Two cationic polyacrylamide samples delivered by Korona, differing in ionic group contents (35\% and 80\%), characterized by weight average molecular weight of $7000 \mathrm{kDa}$ were applied in the study. Using potentiometric titration, the $\mathrm{pK}_{b}$ values of cationic polymer solutions and degrees of cationic groups ionization $(\alpha)$ were determined. The $\mathrm{pK}_{b}$ value of CT PAM 35\% is equal to 9.3 and the dis-

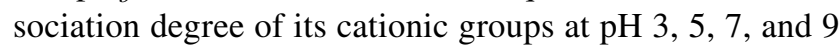
is $99.99 \%, 99.99 \%, 99.44 \%$ and $64 \%$ respectively. In case of CT PAM $80 \%$, the $\mathrm{pK}_{\mathrm{b}}$ value equals 9.5 , whereas $\alpha$ parameter is $99.99 \%(\mathrm{pH} 3), 99.99 \%(\mathrm{pH} \mathrm{5}), 99.68 \%(\mathrm{pH} 7)$ and $75.97 \%$ (pH 9).

\section{Methods}

\section{Adsorption measurements}

All adsorption measurements were carried out by the static method at $\mathrm{pH} 5 \pm 0.1$ (acidic conditions typical of Polish soils) and $25^{\circ} \mathrm{C} . \mathrm{NaCl}\left(0.001 \mathrm{~mol} / \mathrm{dm}^{3}\right)$ was used as the supporting electrolyte. The examined PAM concentrations were in the range $20-150 \mathrm{ppm}$ (adsorption isotherms), whereas $\mathrm{Pb}$ (II) ions- 1,10 , and $100 \mathrm{ppm}$. In the first step the calibration curves for two CT PAM samples and $\mathrm{Pb}$ (II) ions were prepared. In the case of the cationic polyacrylamide the polymer concentration was determined spectrophotometrically at $495 \mathrm{~nm}$ using a UV-VIS spectrophotometer (Carry 100; Varian) and brilliant yellow as an indicator (Wiśniewska et al. 2019a, b). To determine the concentration of lead(II), the reaction of $\mathrm{Pb}$ (II) ions with 4-(2-pyridylazo)-rezorcinol (PAR) in an ammonium buffer (pH 10) was used (Dagnall et al. 1965). The lead content was determined spectrophotometrically at a wavelength of $520 \mathrm{~nm}$. Using the calibration 
curves the amount of adsorbed CT PAM or Pb(II) ions on the montmorillonite surface was calculated from the difference between the polymer or heavy metal ion concentration in the solution before and after its adsorption. This process was carried out under the conditions of continuous shaking (water bath OLS 200, Grant) for $24 \mathrm{~h}$. The montmorillonite weight in each examined system was $0.003 \mathrm{~g}$. The appropriate $\mathrm{pH}$ values of the examined suspensions were adjusted with a $\mathrm{pH}$-meter (Beckman Instruments). The solids were centrifuged using a microcentrifuge (MPW Med. Instruments) and the clear solutions were collected for further analysis of polymer and $\mathrm{Pb}$ (II) ion concentration (with the procedures described above).

The kinetic measurements were performed for the polymer and heavy metal ions concentrations equal to $100 \mathrm{ppm}$. The experiments concerning order of individual adsorbates addition were performed at PAM concentration $100 \mathrm{ppm}$ and $\mathrm{Pb}$ (II) ions concentrations: 1,10 , and $100 \mathrm{ppm}$.

\section{Electrokinetic measurements}

Using the potentiometric titration method the surface charge density as a function of solution $\mathrm{pH}$ as well as a point of zero charge $\left(\mathrm{pH}_{\mathrm{pzc}}\right)$ were determined. The potentiometric titrations of mineral suspensions without and with PAM (100 ppm) and/or $\mathrm{Pb}(\mathrm{II})(100 \mathrm{ppm})$ were carried at $25^{\circ} \mathrm{C}$ in the $\mathrm{pH}$ range $3-7 \pm 0.1$ using $0.1 \mathrm{~g}$ of the adsorbent. The measuring set consisted of: thermostated Teflon vessel (thermostat RE 204, Lauda), glass and calomel electrodes (Beckman Instruments), pH-meter PHM 240 (Radiometer), microburette (Dosimat 765, Methrom), printer and computer with the special program Titr_v3 (Janusz 1994).

The zeta potential of montmorillonite was determined in the $\mathrm{pH}$ range from 3 to 7 at $25{ }^{\circ} \mathrm{C}$. The montmorillonite suspensions in the $\mathrm{NaCl}$ solution $\left(0.001 \mathrm{~mol} / \mathrm{dm}^{3}\right)$ without and with PAM (100 ppm) and/or Pb(II) (100 ppm) were prepared by adding $0.1 \mathrm{~g}$ of mineral to $100 \mathrm{~cm}^{3}$ of the appropriate solution. Each suspension was sonicated for $3 \mathrm{~min}$ (ultrasonicator XL 2020, Misonix) and separated into seven parts (of different $\mathrm{pH}$ values changing in the range 3-7). The polymer was introduced after the process of solid suspension sonication. The electrophoretic mobility of the systems was measured using Zetasizer Nano ZS (Malvern Instruments) with the universal dip cell at $25^{\circ} \mathrm{C}$. The zeta potential value was calculated from of electrophoretic mobility of solid particles in the liquid medium using the Henry equation (Hunter 1981).

\section{Thermal analysis}

Thermal properties of samples unmodified and modified with cationic polyacrylamide and/or $\mathrm{Pb}$ (II) ions (both adsorbates had initial concentrations 100 ppm) were determined using the simultaneous thermal analyzer STA 449 F1 Jupiter (Netzsch, Germany). The TG, differential TG (DTG) and differential scanning calorimetry (DSC) curves were recorded over the $30-950{ }^{\circ} \mathrm{C}$ range at a heating rate of $10{ }^{\circ} \mathrm{C} / \mathrm{min}$ in the synthetic air atmosphere $(50 \mathrm{~mL} / \mathrm{min})$ using a sensor of thermocouple type S TG-DSC. The samples: mass $\sim 10 \mathrm{mg}$ (in helium atmosphere) and mass $\sim 7 \mathrm{mg}$ (in air atmosphere) were placed in an alumina crucible. An empty $\mathrm{Al}_{2} \mathrm{O}_{3}$ crucible was used as a reference. The gaseous products emitted during decomposition of materials were analyzed by FTIR spectrometer Tensor 27 (Brucker Optik GmbH, Germany) and by QMS 403D Aeölos (Netzsch, Germany) coupling on-line to the thermal analyzer. The data were collected and processed using the NETZSCH Proteus ${ }^{\circledR}$ software, version 6.1 .

\section{Aggregation study}

Aggregation tendency of montmorillonite unmodified and modified with cationic polyacrylamide and/or $\mathrm{Pb}$ (II) ions (both adsorbates had initial concentrations $100 \mathrm{ppm}$ ) were performed using turbidimeter (Hach AN2100, Omc Envag) and CPS analyzer (CPS Instruments) with DCS (Differential Centrifugal Sedimentation) technique. The samples were prepared by the addition of $0.05 \mathrm{~g}$ to the solution containing supporting electrolyte. After 2-min sonication, the solution $\mathrm{pH}$ was adjusted to the value of 5 . Then, the $\mathrm{Pb}$ (II) and/or cationic polyacrylamide was added to the system and the measurements were started. The concentration of CT PAM and $\mathrm{Pb}$ (II) equaled $100 \mathrm{ppm}$. Turbidimeter recorded changes in suspension turbidity over time (i.e. $0,2,5,10,30,60$, and $90 \mathrm{~min}$ from the start of the measurement). In turn, the CPS analyzer determined the diameter of particles/aggregates present in the examined systems. The disc rate was about $2500 \mathrm{rpm} .8 \%$ and $24 \%$ sucrose were used in the gradient formation. The particle/aggregate size was measured in the range of $0.3-15 \mu \mathrm{m}$.

\section{Results and discussion}

\section{Adsorption and electrokinetic properties of montmorillonite regards to cationic PAM and $\mathrm{Pb}$ (II) ions in the systems containing single adsorbate}

The cationic polyacrylamide and $\mathrm{Pb}$ (II) ions adsorbed amounts on the montmorillonite surface are presented in Figs. 1 and 2, whereas the adsorption kinetics for these substances are presented in Fig. 3. These results showed that the time required to reach an equilibrium state in the examined systems was about $1 \mathrm{~h}$. Moreover, the higher adsorbed amount was observed for cationic polyacrylamide with a

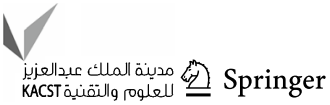




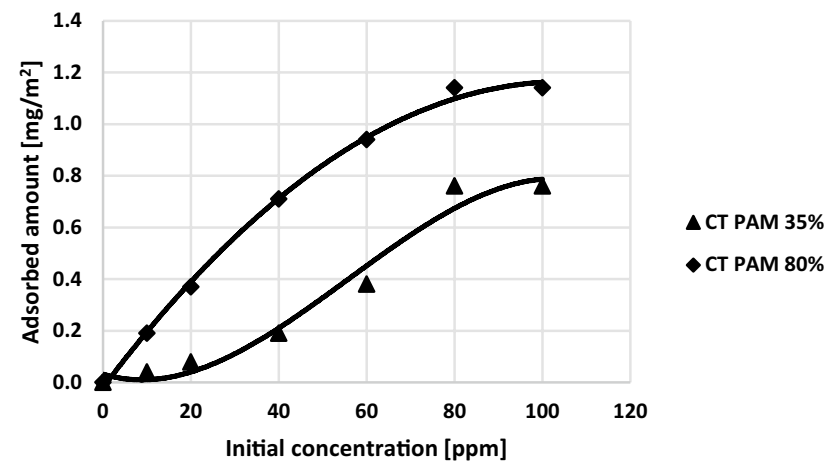

Fig. 1 The cationic PAM adsorption isotherms on the montmorillonite surface at $\mathrm{pH} 5$

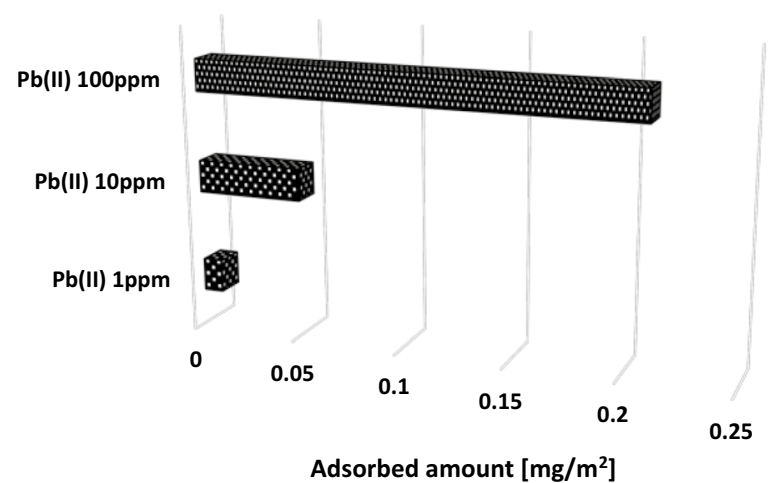

Fig. 2 Adsorbed amount of $\mathrm{Pb}(\mathrm{II})$ ions on the montmorillonite surface at $\mathrm{pH} 5$

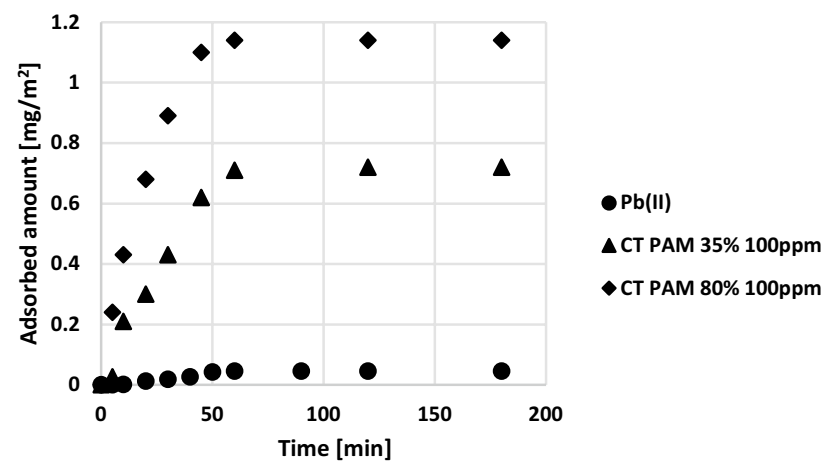

Fig. 3 CT PAM and $\mathrm{Pb}(\mathrm{II})$ ions adsorption kinetics higher content of cationic groups (CT PAM 80\%). At pH 5 the dissociation degree of quaternary amine groups located in the polymer chains is equal to $99.99 \%$, which means that macromolecules are totally ionized. Higher adsorbed amount observed for CT PAM 80\% (compared to CT PAM 35\% one) is the result of different conformation of its macromolecules on the montmorillonite surface. CT PAM $80 \%$, due to higher content of positive groups, assumes more expanded conformations than CT PAM 35\% forming a longer loop and tail structures during the adsorption process. As a consequence, a single CT PAM $80 \%$ macromolecule take a smaller part of the solid surface and a greater number of them can be adsorbed on the unit area of montmorillonite.

Potentiometric titration results (Table 1) showed that at $\mathrm{pH}$ close to 5 the total surface charge of the solid $\left(\sigma_{0}\right)$ is equal to zero (point of zero charges of-pzc of montmorillonite is at $\mathrm{pH}$ 5.02). Under such conditions, the concentrations of the positively $\left(-\mathrm{SOH}_{2}^{+}\right)$and negatively $\left(-\mathrm{SO}^{-}\right)$ charged surface groups are the same. This means that electrostatic interactions are not an important factor determining the polyacrylamide adsorbed amount on the clay mineral surface at $\mathrm{pH}$ 5. The CT PAM addition causes an increase in the solid surface charge density compared to the system without the polymer. At studied $\mathrm{pH}$ range positively charged quaternary amine PAM groups are very numerous and, due to their adsorption, a clear increase, especially for CT PAM $80 \%$, in the $\sigma_{0}$ parameter is observed. The great number of these groups are not bounded directly with the solid surface, but are located in the by-surface layer in tail and loop structures of adsorbed PAM chains.

In turn, the zeta potential of montmorillonite is negative in the whole studied $\mathrm{pH}$ range and the $\mathrm{pH}_{\text {iep }}$ (isoelectric point) value is lower than 3 (Table 1). At $\mathrm{pH} 5$, the montmorillonite $\zeta$ parameter is about $-11.1 \mathrm{mV}$. The adsorption of CT PAM 35\% and CT PAM 80\% causes significant changes in the mineral electrokinetic potential, i.e. there is an increase in zeta potential values compared to the system without polymers. These changes are mainly associated with the shift of slipping plane caused by adsorbed macromolecules of considerable sizes as well as the presence of positively charged functional PAM groups in the slipping plane area. Greater impact on zeta potential value is observed for CT PAM $80 \%$, which contains a greater number of dissociable groups containing quaternary amine fragments.
Table 1 Surface charge density $\left(\sigma_{0}\right)$ and zeta potential $(\zeta)$ of montmorillonite particles in the absence and presence of CT PAM and/or Pb(II) ions measured at $\mathrm{pH} 5$

\begin{tabular}{llr}
\hline System & $\sigma_{0}\left[\mu \mathrm{C} / \mathrm{cm}^{2}\right]$ & $\zeta[\mathrm{mV}]$ \\
\hline Montmorillonite & 0 & -11.1 \\
Montmorillonite + CT PAM 35\% 100 ppm & 0.15 & 11.4 \\
Montmorillonite + CT PAM $80 \% 100 \mathrm{ppm}$ & 2.71 & 16.1 \\
Montmorillonite + Pb(II) $1 \mathrm{ppm}$ & -0.1 & -11.5 \\
Montmorillonite + Pb(II) 1 ppm/CT PAM 35\% $100 \mathrm{ppm}$ & 4.03 & 13.3 \\
Montmorillonite + Pb(II) 1 ppm/CT PAM $80 \% 100 \mathrm{ppm}$ & 5.32 & 19.3 \\
\hline
\end{tabular}


Lead(II) ions undergo adsorption on the montmorillonite surface at $\mathrm{pH}$ 5. This process is mainly caused by the ionexchange process. The $\mathrm{Pb}$ (II) ions undergo exchange with so-called interlayered cations present in the spaces between silica and alumina species (Uddin 2008; Ait Bentaleb et al. 2016). Moreover, the presence of lead(II) cations in the system changes $\sigma_{0}$ parameter-there is a slight reduction in montmorillonite surface charge density (Wiśniewska et al. 2017). According to the site-binding model, this phenomenon is based on the following interactions:

$\equiv \mathrm{SOH}+\mathrm{Ct}^{2+} \leftrightarrow \equiv \mathrm{SO}^{-} \mathrm{Ct}^{2+}+\mathrm{H}^{+}$,

$2(\equiv \mathrm{SOH})+\mathrm{Ct}^{2+} \leftrightarrow(\equiv \mathrm{SO})_{2} \mathrm{Ct}^{2+}+2 \mathrm{H}^{+}$,

$\equiv \mathrm{SOH}+\mathrm{Ct}^{2+}+\mathrm{H}_{2} \mathrm{O} \leftrightarrow \equiv \mathrm{SO}^{-} \mathrm{CtOH}^{+}+2 \mathrm{H}^{+}$.

The $\mathrm{Pb}(\mathrm{II})$ addition causes a slight decrease in mineral zeta potential value. Heavy metal ions adsorb on the solid surface and, as a consequence, positive charge accumulation on montmorillonite particles is observed. This charge is neutralized by negative moieties located in the slipping plane area.

\section{Adsorption and electrokinetic properties of montmorillonite regards to cationic PAM and $\mathrm{Pb}(\mathrm{II})$ ions in the systems containing mixed adsorbates}

In the examined systems the order of adsorbates addition, as well as lead(II) ions concentration, have a minimal effect on the CT PAM 35\% and CT PAM 80\% adsorbed amount on montmorillonite surface (Fig. 4a, b). At pH 5 both polyacrylamide macromolecules have developed conformation due to the presence of positively charged groups in the polymer chains (especially in the case of CT PAM 80\%). Thus, the cationic polymer macromolecules are too large to penetrate the montmorillonite pores $(5.9 \mathrm{~nm})$ and internal mineral structure. On the other hand, lead(II) ions have such a small size that they can freely enter the interlayer space of montmorillonite, even when the polymer is adsorbed on the mineral surface. A small decrease in the PAM adsorbed amount noted in the presence of $100 \mathrm{ppm} \mathrm{Pb}$ (II) may be associated with electrostatic repulsion between cationic polymer quaternary amine groups and lead(II) cations.

As can be seen in Fig. 5a the order of polymer and heavy metal ion addition to the examined system has minimal effect on the $\mathrm{Pb}(\mathrm{II})$ ions adsorption on the montmorillonite surface. In case of lowest concentration of lead(II) ions $(1 \mathrm{ppm})$, the addition of the cationic polyacrylamide (both CT PAM 35\% and CT PAM 80\%) does not affect the lead cations adsorbed amount on montmorillonite surface. It is (a)

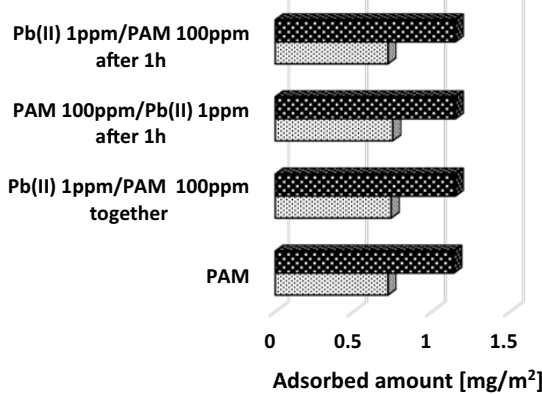

DCT PAM $80 \% 100 \mathrm{ppm}$

BCT PAM 35\% 100ppm

(b)

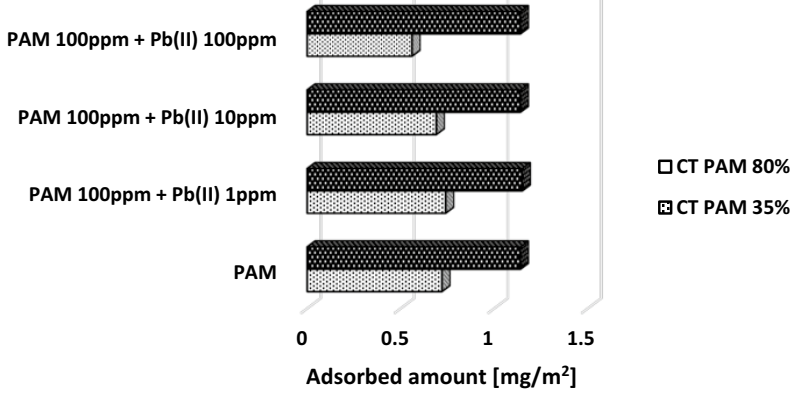

Fig. 4 Cationic polyacrylamide adsorbed amount on the montmorillonite surface: a effect of the order of CT PAM and lead(II) ions addition, $\mathbf{b}$ effect of concentration of $\mathrm{Pb}$ (II) ions, both adsorbates were added together

(a)

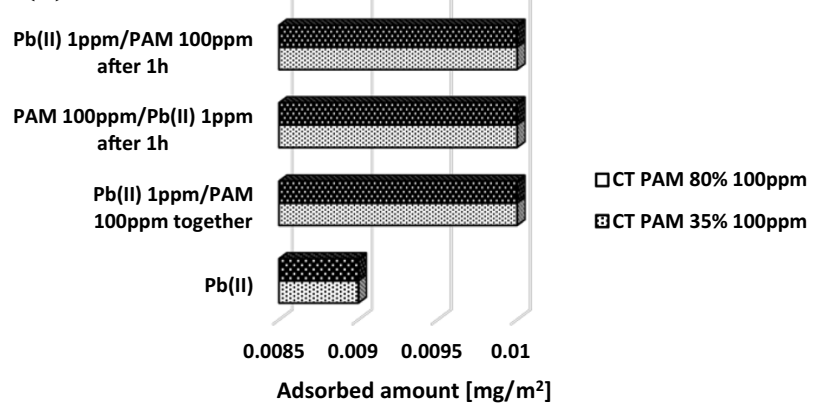

(b)

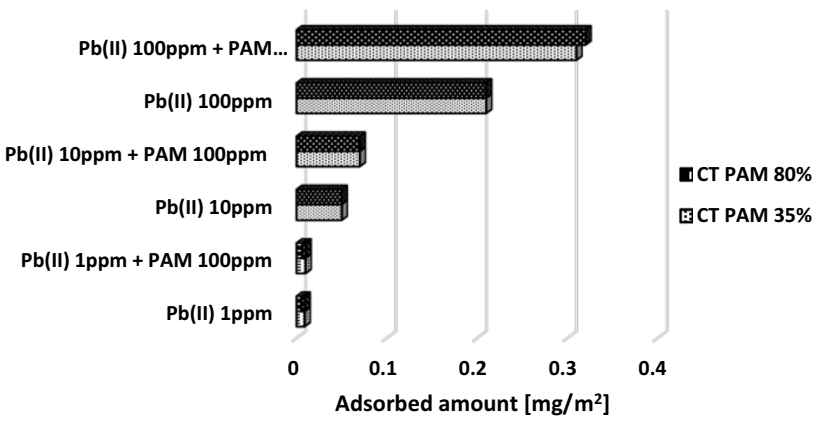

Fig. $5 \mathrm{~Pb}$ (II) ions adsorbed amount on the montmorillonite surface: a effect of the order of CT PAM and lead(II) ions addition, $\mathbf{b}$ effect of CT PAM presence, both adsorbates were added together 
such a small concentration, that all lead(II) ions undergo adsorption process by ion exchange. However, in the systems with lead(II) ions of concentrations of 10 or $100 \mathrm{ppm}$, a slight increase in their adsorption in the presence of cationic polyacrylamide is observed (Fig. 5b). PAM chains contain the quaternary amine fragments (which are the source of positive charges) as well as neutral amide groups. The freeelectron pairs located on the nitrogen atoms of polyacrylamide amide groups are probably involved in covalent bond formation between PAM and lead(II) ions (Gu et al. 2018; Zhao et al. 2009; Zhou et al. 2011; Li et al. 2005). This indicates that, despite electrostatic repulsion between positively charged ionized polymer groups and $\mathrm{Pb}(\mathrm{II})$ cations, the heavy metal can be immobilized and the accumulation phenomenon occurs. Moreover, the competitive adsorption of both adsorbates with the same sign of charge can take place.

The adsorption of $\mathrm{Pb}$ (II)-PAM complexes also contributes to an increase in surface charge density of clay mineral (Table 1). This indicates that, within the adsorbed complexes, ionized groups are located in non-adsorbed fragments. The adsorption of $\mathrm{Pb}$ (II)-PAM complexes makes zeta potential more positive. This is the result of the presence of positively charged amine groups in loops and tails structures of adsorbed macromolecules in the slipping plane area.

\section{Thermal degradation of unmodified montmorillonite and its composites with cationic polyacrylamide and/or $\mathrm{Pb}$ (II) ions}

Figures 6 and 7 present TG, DTG and DSC curves of unmodified montmorillonite and montmorillonite modified with $\mathrm{Pb}$ (II) ions, CT PAM 35\%, CT PAM $80 \%$ as well as montmorillonite modified with mixed adsorption layers of CT PAM 35\% + Pb(II) and CT PAM 80\% + Pb(II).

The thermal decomposition of montmorillonite in the atmosphere consists of two stages (Fig. 6, solid line). 1.32\% weight loss in the temperature range up to $200{ }^{\circ} \mathrm{C}$ results from the removal of physically bound water and dehydration of hydration layers of cations present in the structure of montmorillonite. Dehydroxylation processes occur in the temperature range of $200-900{ }^{\circ} \mathrm{C}$, as evidenced by the peaks on the DTG curves corresponding to temperatures of 477 and $563{ }^{\circ} \mathrm{C}$ (Sternik et al. 2017; Gładysz-Płaska et al. 2010; Onal and Sarikaya 2007). Peaks on DSC curves confirm that they are endothermic processes. The presence of an additional endothermic peak on the DSC curve with a maximum at $577{ }^{\circ} \mathrm{C}$ is associated with phase transition within quartz. These results are consistent with the literature data (Mothé and Ambrósio 2007; Moore 1993; Sternik et al. 2019a, b) and mass spectra presented in Fig. 10a and $b$ for $M / Z=18$ and 44 .
In the case of a montmorillonite sample modified with $\mathrm{Pb}$ (II) ions (Fig. 6b), an increase in the amount of water removed by approx. $0.7 \%$ compared to the starting material was observed in the temperature range up to $200{ }^{\circ} \mathrm{C}$, which is the result of cation exchange in the mineral structure. At higher temperatures, a weight loss of $4.04 \%$ is mainly associated with dehydroxylation, as is the case with unmodified aluminosilicate. This process is multi-stage, as evidenced by the peaks on the DTG curves at 465,574 , and $746^{\circ} \mathrm{C}$.

Figure 6 (long dash line and long-short-short line) show TG, DTG, and DSC curves for thermal decomposition of montmorillonite samples modified with a cationic polymer. As in the case of the initial sample, weight losses in the temperature range up to $200{ }^{\circ} \mathrm{C}$ result from the dehydration process. However, noticeable differences were observed at higher temperatures, as evidenced by larger weight losses, i.e. $5.5 \%$ in the presence of CT PAM $35 \%$ and $7.7 \%$ for CT PAM $80 \%$. In the temperature range of $200-425{ }^{\circ} \mathrm{C}$, exothermic peaks on DSC and DTG curves are mainly associated with the degradation of organic matter adsorbed on the surface of montmorillonite (Kitahara et al. 2012; Jayaramudu et al. 2019). As indicated MS data (Fig. 8), the main degradation products are $\mathrm{H}_{2} \mathrm{O}$ and $\mathrm{CO}_{2}$. The increase in peak intensity on the MS curves for a CT PAM $80 \%$ modified sample is due to the greater adsorbed amount of this polymer compared to CT PAM $35 \%$. The presence of two distinct peaks on the DTG curves at 245 and $341{ }^{\circ} \mathrm{C}$ (Fig. 6, long-short-short line) indicates the differential mechanism of adsorption- using van der Waals forces and electrostatic interactions. Similar effects were observed in the case of adsorption of cationic surfactants (Yariv and Cross 2002; He et al. 2006; Sternik et al. 2017). Processes occurring at higher temperatures are the result of further oxidation of carbon residues after the breakdown of macromolecules and dehydroxylation of aluminosilicate.

Adsorption studies have shown that in mixed adsorbate systems an increase in the affinity of $\mathrm{Pb}$ (II) ions for the surface of montmorillonite modified with a cationic polymer has been obtained. These effects affect the thermal stability of these systems (Fig. 7a-c). Similarly to the previously discussed samples in the first dehydration stage, these changes are small compared to the montmorillonite $+\mathrm{CT}$ PAM samples. This is demonstrated by similar mass losses and similar peak temperature values on the DTG curves. In the second stage greater changes were observed for the sample containing CT PAM 80\% (Fig. 7, dotted line). In the case of montmorillonite $+\mathrm{CT}$ PAM $80 \%+\mathrm{Pb}$ (II) composite, weight losses on TG curves and broad DTG peaks (Fig. 7a, b) are caused by polymer decomposition and mineral dehydroxylation, similarly to the montmorillonite + CT PAM $80 \%$ sample. The disappearance of DTG peaks in the $200-425^{\circ} \mathrm{C}$ temperature range indicates the change of the interactions within the composite structure. This is the result 
(a)

(b)

TG $/ \%$

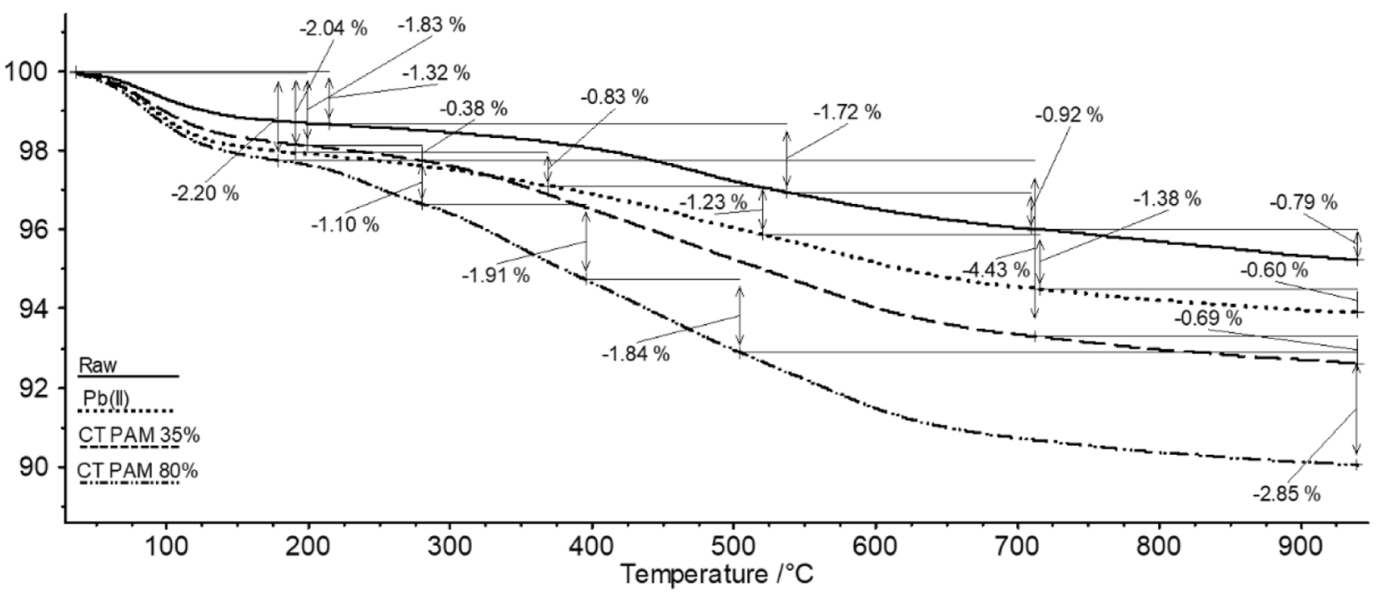

DTG /(\%/min)

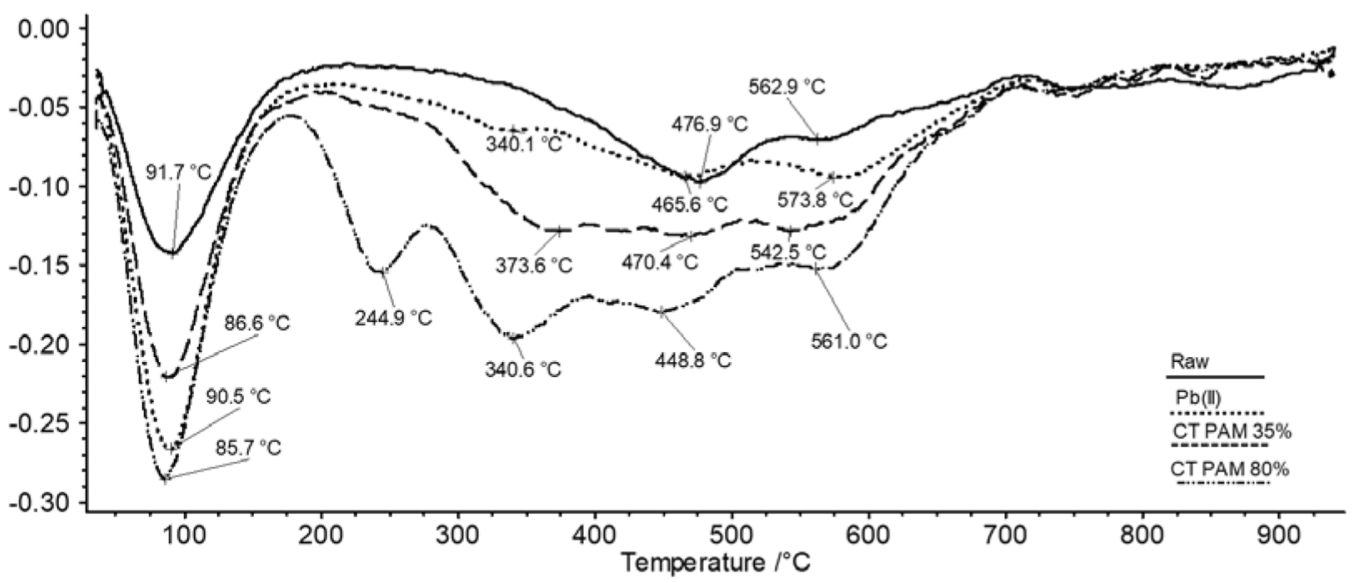

(c)

$\mathrm{DSC} /(\mathrm{mW} / \mathrm{mg})$

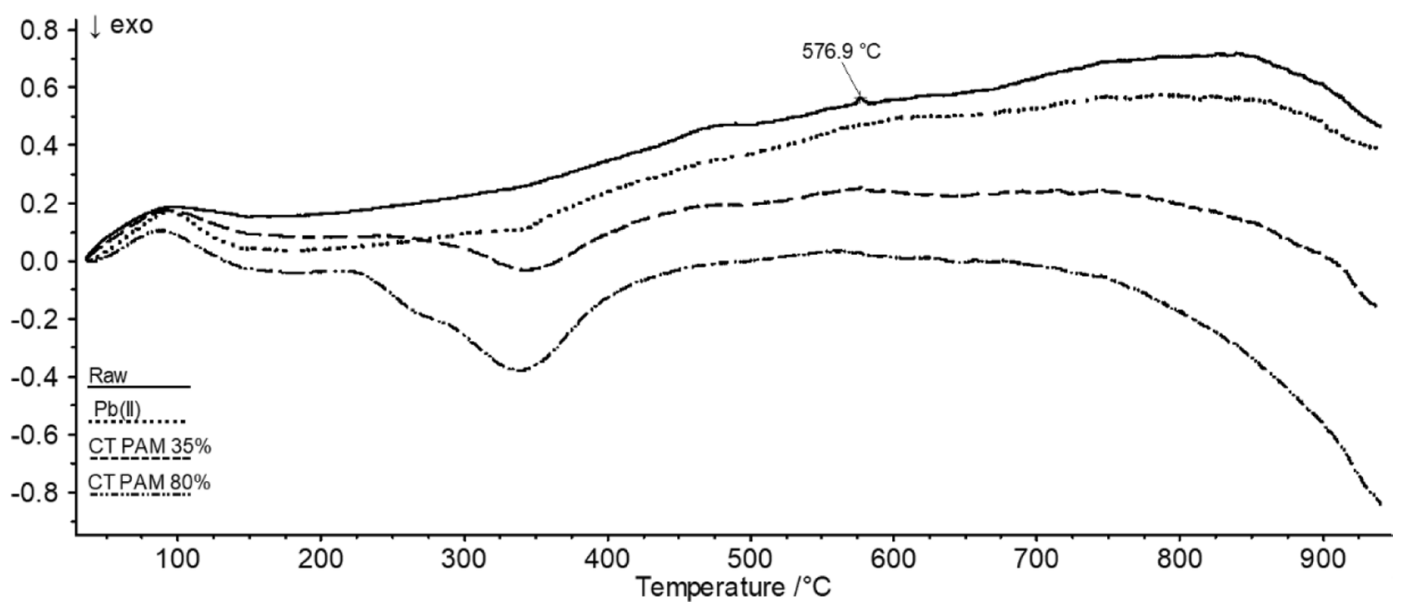

Fig. 6 TG (a), DTG (b) and DSC (c) curves of unmodified montmorillonite (solid line) and montmorillonite modified with $\mathrm{Pb}$ (II) ions (dotted line), CT PAM 35\% (long dash line) and CT PAM 80\% (long- short-short line) obtained at $\mathrm{pH} 5$ for the initial concentration of polymer $100 \mathrm{ppm}$ in the air atmosphere 
(a)

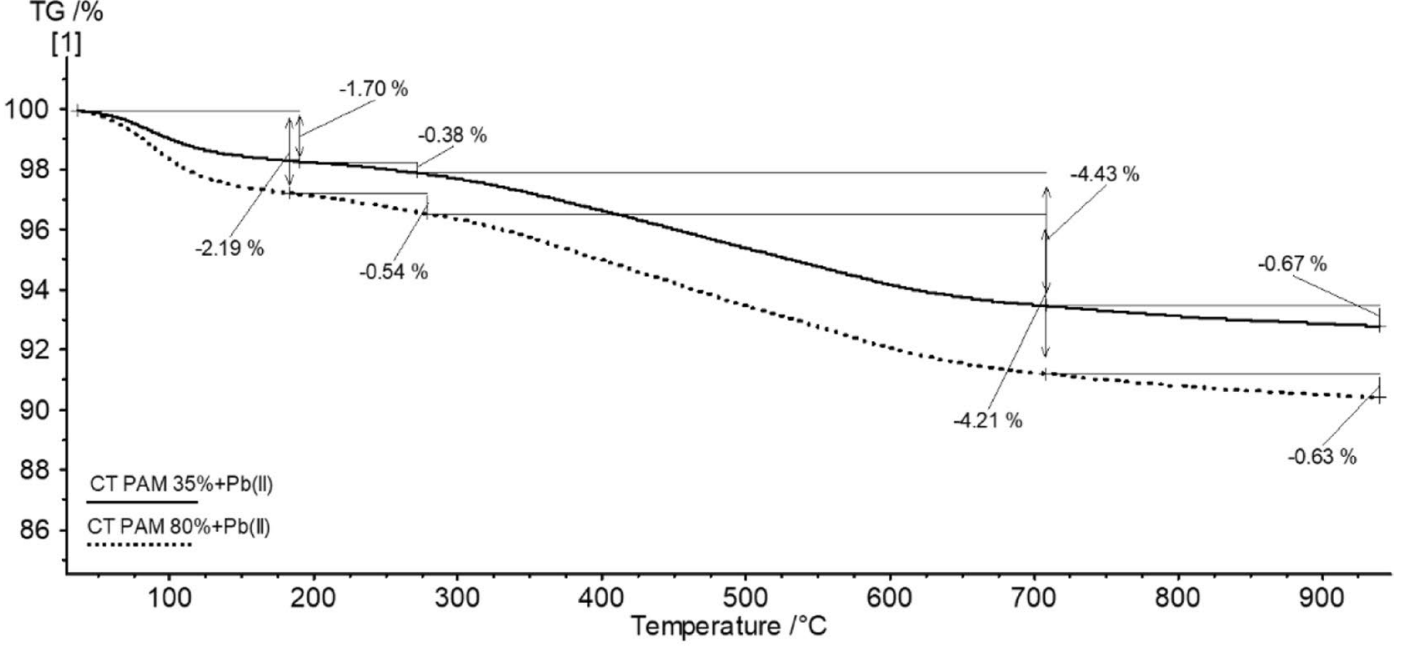

(b)

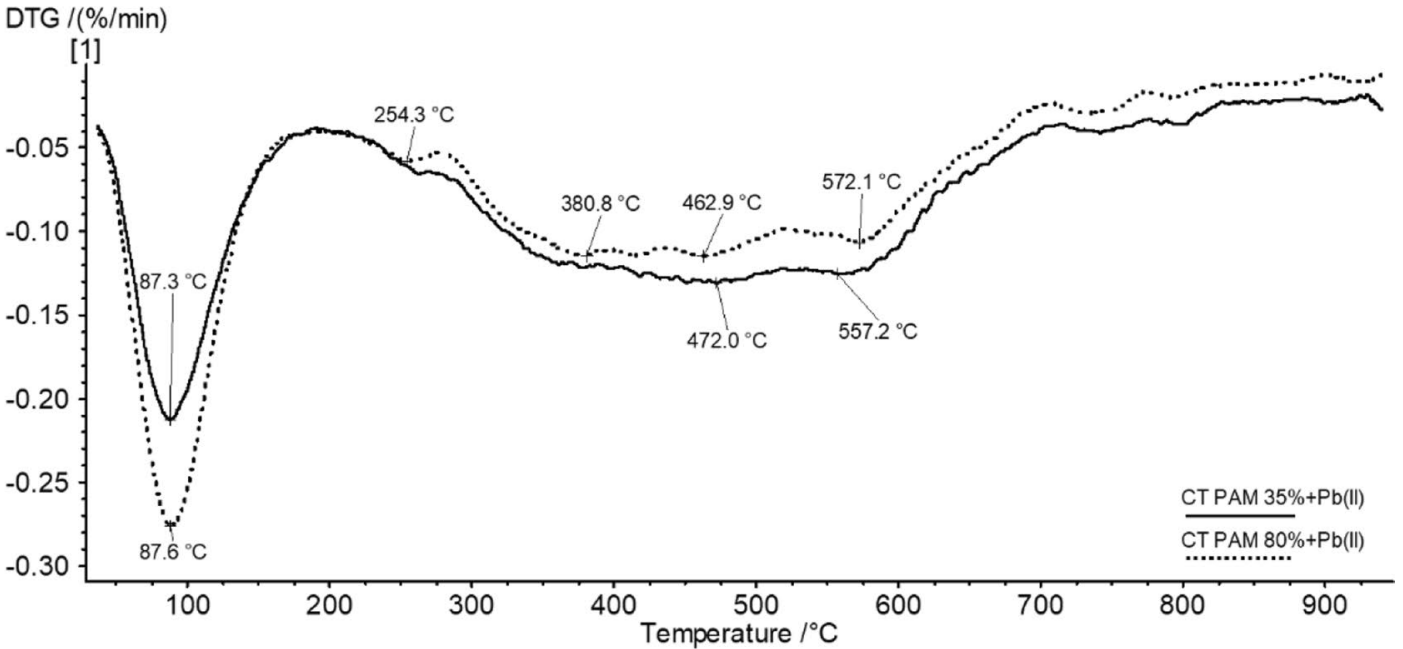

(c)

$\mathrm{DSC} /(\mathrm{mW} / \mathrm{mg})$

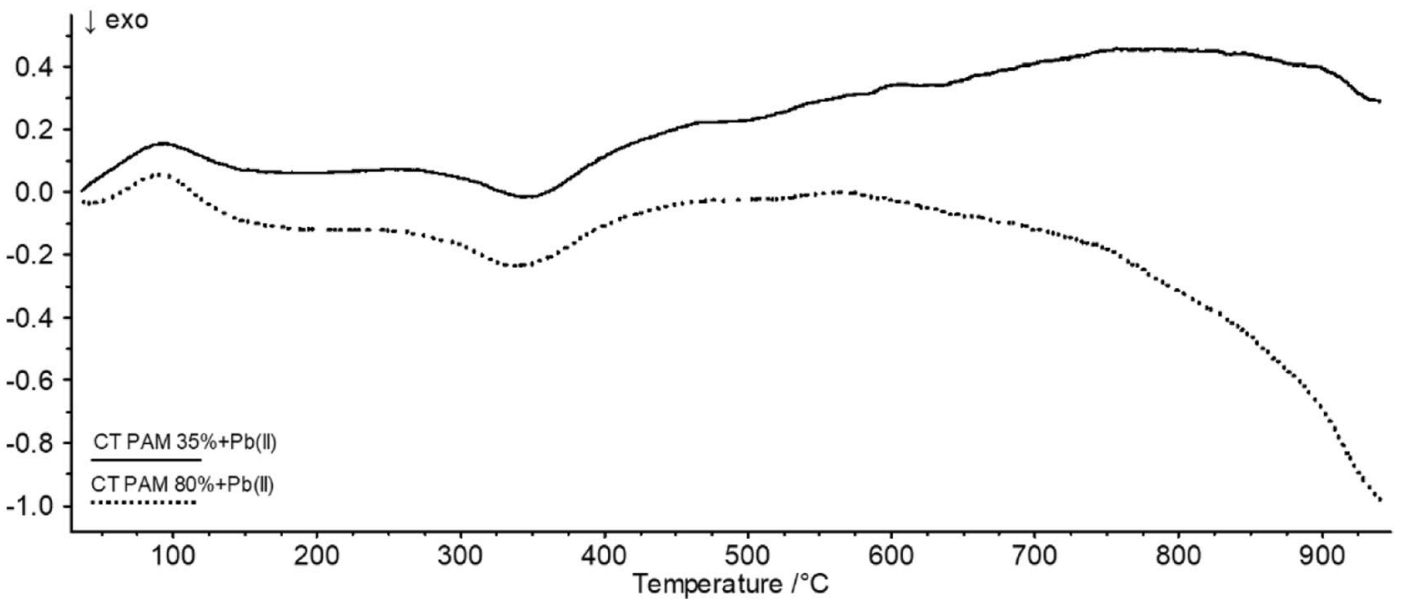

Fig. 7 TG (a), DTG (b) and DSC (c) curves of montmorillonite modified with mixed adsorption layers of CT PAM $35 \%+\mathrm{Pb}$ (II) (solid line) and CT PAM $80 \%+\mathrm{Pb}$ (II) (dotted line) obtained at $\mathrm{pH} 5$ for the initial concentration of polymer and heavy metal ions $100 \mathrm{ppm}$ and in the air atmosphere 
(a)

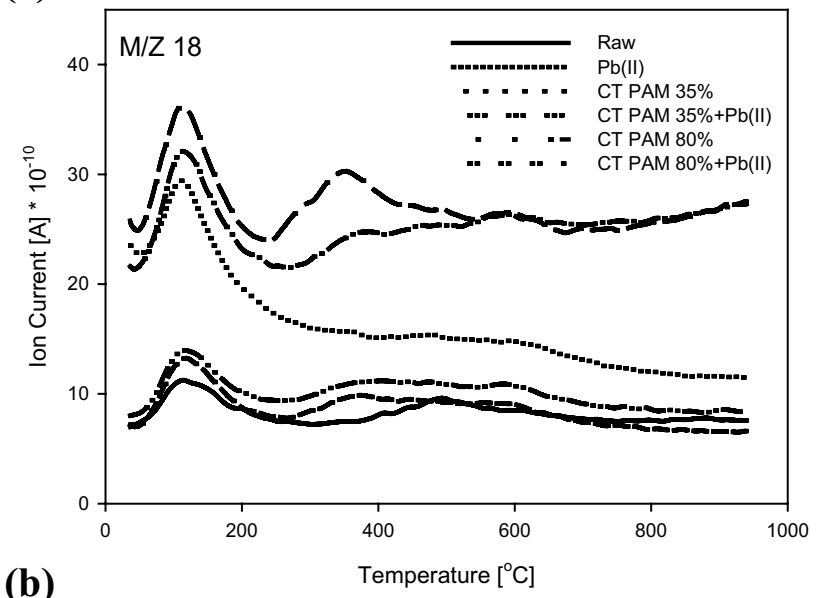

(b)

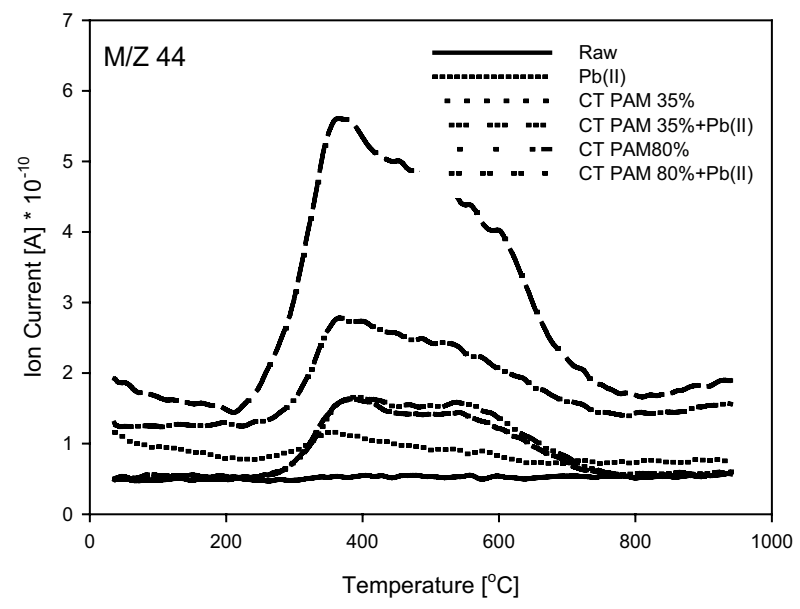

Fig. 8 MS profiles of gaseous products $\left[\mathrm{H}_{2} \mathrm{O}(\mathbf{a})\right.$ and $\left.\mathrm{CO}_{2}(\mathbf{b})\right]$ of thermal degradation in the air of unmodified montmorillonite and montmorillonite modified simple and mixed adsorbates

of the formation of complexes between polymer chains and lead(II) ions, which confirms earlier assumptions about their chemical nature and interactions with the participation of polymer amide groups.

\section{Aggregation of unmodified montmorillonite and its composites with cationic polyacrylamide and/ or $\mathrm{Pb}(\mathrm{II})$ ions}

The study on the aggregation tendency of montmorillonite unmodified and modified with cationic polyacrylamide and/or $\mathrm{Pb}$ (II) ions was performed using both turbidimeter and CPS analyzer (Figs. 9, 10). As can be seen, montmorillonite in the suspension without heavy metal ions and polymer is characterized by relatively high stability. After $60 \mathrm{~min}$, the turbidity of this system equals $126 \mathrm{NTU}$ and is the highest among all tested samples. At pH 5, the electrokinetic potential of montmorillonite particles is $-11.1 \mathrm{mV}$,
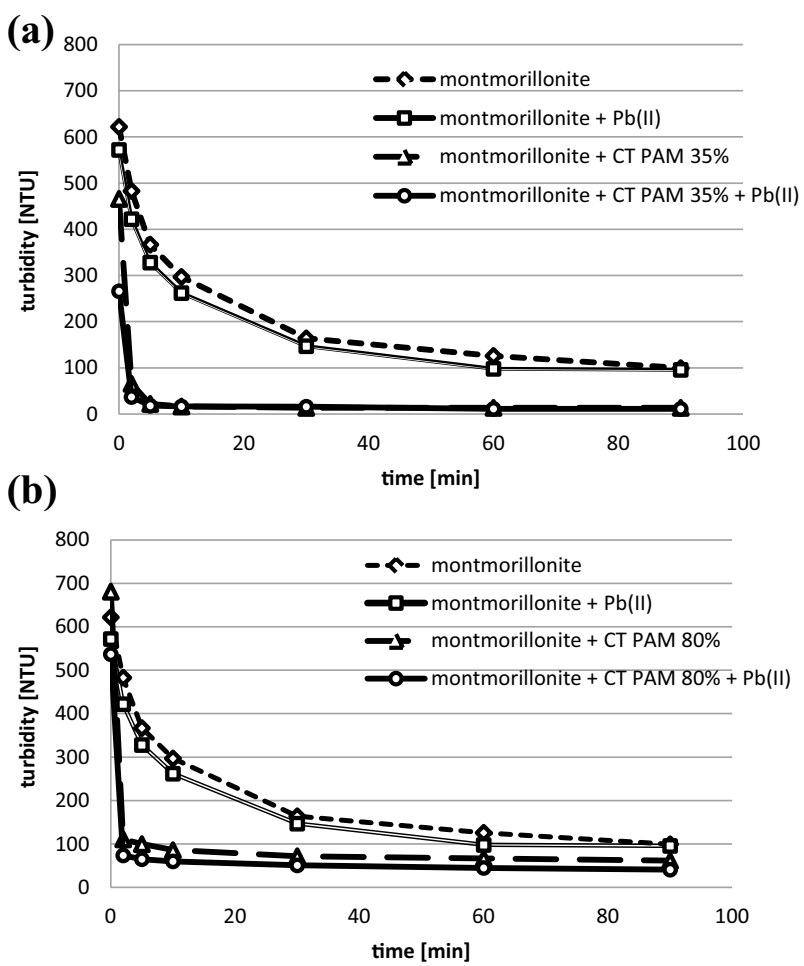

Fig. 9 Turbidity changes over time obtained for montmorillonite suspensions without and with $\mathrm{Pb}$ (II) ions and a CT PAM $35 \%$ or b CT PAM $80 \%$

which means that there are electrostatic repulsive forces between them limiting the solid aggregation. Under these conditions, the diameter of the most numerous particles/ aggregates in the system equals $0.44 \mu \mathrm{m}$.

$\mathrm{Pb}$ (II) ions addition slightly affects the montmorillonite aggregation. The size of most particles/aggregates is $0.66 \mu \mathrm{m}$. It is probably dictated by very similar values of montmorillonite zeta potential without and with $\mathrm{Pb}(\mathrm{II})$ ions (i.e. -11.1 and $-11.5 \mathrm{mV}$, respectively). The turbidity of the suspension containing heavy metal ions, noted after $60 \mathrm{~min}$, is 98 NTU.

The cationic polyacrylamide modification changes the montmorillonite aggregation significantly. There is a strong aggregation in the system. A large decrease in the system turbidity was observed just after the first $2 \mathrm{~min}$. The particle size clearly increased. After $60 \mathrm{~min}$, in the case of CT PAM 35\%, the suspension turbidity does not exceed 14 NTU, whereas in the case of CT PAM $80 \%$ 67 NTU. Probably, the adsorbed macromolecules form specific bridges between particles, which stimulates their aggregation (flocculation). The $\mathrm{Pb}$ (II) ions presence does not reduce the flocculating ability of the used cationic polyacrylamides. Large aggregates are also observed when the montmorillonite is modified by $\mathrm{Pb}$ (II) ions and $\mathrm{CT}$ PAM simultaneously. 


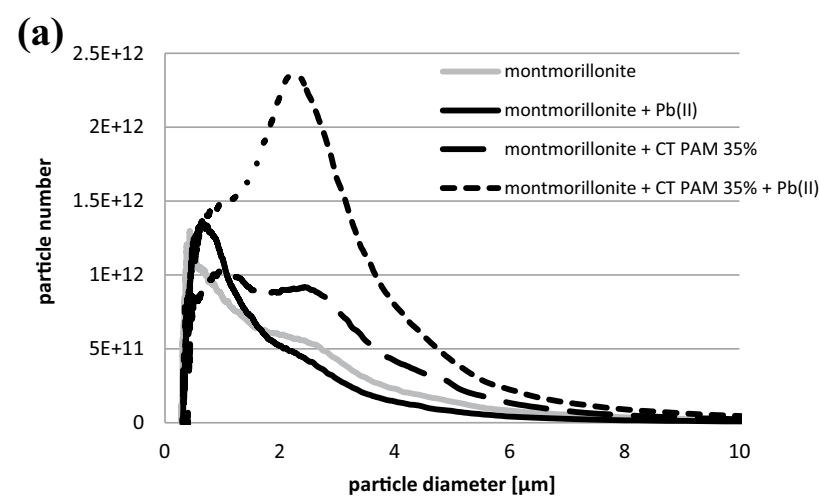

(b)

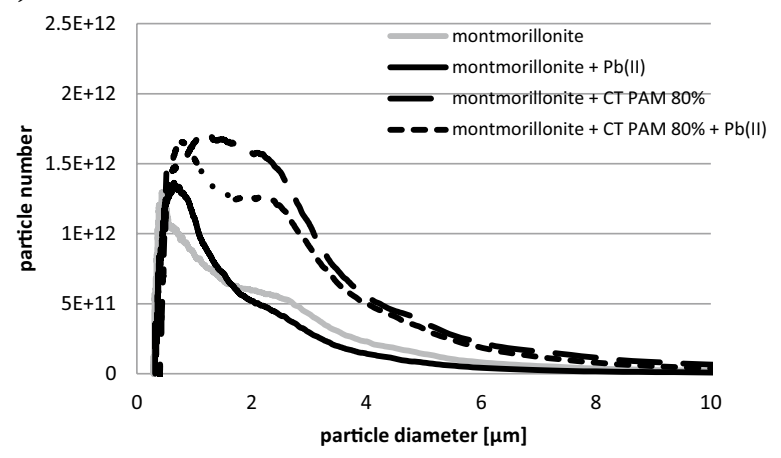

Fig. 10 Particle number vs. particle diameter obtained for montmorillonite suspensions without and with $\mathrm{Pb}$ (II) ions and a CT PAM 35\% or b CT PAM $80 \%$

The aggregation properties of ionic polyacrylamides and polyamino acid block copolymers in relation to chromium(III) oxide particles leading to their separation from liquid phase were examined in our previous papers (Wiśniewska et al. 2015, 2019a, b; Ostolska and Wiśniewska 2015).

\section{Conclusions}

Based on the adsorption, electrokinetic, thermal stability and aggregation results it can be stated that montmorillonite soil mineral particles covered with cationic polyacrylamide layers effectively immobilize hazardous lead(II) ions, leading to increase of aggregation possibilities of such systems. The detailed conclusions were as follows:

(1) Higher adsorbed amount of cationic polyacrylamide on the montmorillonite surface is observed for the polymer with a greater number of cationic groups (more extended conformation on the solid surface).

(2) Order of the addition of adsorbates has practically no effect on the adsorbed amounts of both cationic polyacrylamide and lead(II) ions.
(3) The lead(II) ions concentration has a minimal effect on the CT PAM 35\% and CT PAM 80\% adsorbed amounts on the montmorillonite surface.

(4) Despite electrostatic repulsion between positively charged ionized groups of CT PAM and $\mathrm{Pb}$ (II) cations, this heavy metal undergoes immobilization due to the formation of a covalent bond between amide PAM groups and $\mathrm{Pb}(\mathrm{II})$ ions.

(5) Montmorillonite surface modification by lead(II) ions and cationic polyacrylamide affects mineral electrokinetic properties (surface charge density and zeta potential).

(6) Presence of CT PAM and mixed CT PAM $+\mathrm{Pb}$ (II) adsorption layers influences the thermal decomposition of montmorillonite - the analysis of these data confirmed the assumed mechanism of adsorption in the studied systems.

(7) Montmorillonite modification by cationic polyacrylamide stimulates the particle aggregation.

(8) $\mathrm{Pb}(\mathrm{II})$ ions do not limit the cationic polyacrylamide flocculating ability relative to montmorillonite.

\section{Compliance with ethical standards}

Conflict of interest On behalf of all authors, I state that there is no conflict of interest.

Open Access This article is licensed under a Creative Commons Attribution 4.0 International License, which permits use, sharing, adaptation, distribution and reproduction in any medium or format, as long as you give appropriate credit to the original author(s) and the source, provide a link to the Creative Commons licence, and indicate if changes were made. The images or other third party material in this article are included in the article's Creative Commons licence, unless indicated otherwise in a credit line to the material. If material is not included in the article's Creative Commons licence and your intended use is not permitted by statutory regulation or exceeds the permitted use, you will need to obtain permission directly from the copyright holder. To view a copy of this licence, visit http://creativecommons.org/licenses/by/4.0/.

\section{References}

Adachi Y (1995) Dynamic aspects of coagulation and flocculation. Adv Colloid Interface Sci 56:1-31

Agassi M, Letey J, Farmer WJ, Clark P (1995) Soil erosion contribution to pesticide transport by furrow irrigation. J Environ Qual 24:892-895

Ait Bentaleb K, El Khattabi E, Lakraim M, Benaziz L, Sabbar E, Berraho M, Legrouri A (2016) Removal of Cr(VI) from wastewater by anionic clays. J Mater Environ Sci 7:2886-2896

Bajpai AK (1997) Interface behaviour of ionic polymers. Prog Polym Sci 22:523-564 
Carter DL (1993) Furrow erosion lowers soil productivity. J Irrig Drain Eng 11:964-974

Chaney RL, Malik M, Li YM, Brown SL, Brewer EP, Angle JS (1998) Phytoremediation of soil metals. Curr Opin Biotechnol 8:279-284

Dagnall RM, West TS, Young P (1965) Determination of lead with 4-(2-pyridylazo)-resorcinol-I: spectrophotometry and solvent extraction. Talanta 12:583-588

Elimelech M, Gregory J, Jia X, Williams R (1995) Particle deposition and aggregation: measurement, modeling, and simulation. Butterworth-Heinemann, Oxford

Gładysz-Płaska A, Majdan M, Sternik D, Pikus S, Zięba E (2010) Sorptive and thermal properties of red clay in relation to $\mathrm{Cr}(\mathrm{VI})$. J Therm Anal Calorim 101:775-778

Gu S, Wang L, Mao X, Yang L, Wang C (2018) Selective adsorption of $\mathrm{Pb}$ (II) from aqueous solution by triethylenetetramine-grafted polyacrylamide/vermiculite. Materials 11:514

He H, Frost RL, Bostrom T, Yuan P, Duong L, Yang D, Xi Y, Kloprogge JT (2006) Changes in the morphology of organoclays with HDTMA+ surfactant loading. Appl Clay Sci 31:262-271

Hunter RJ (1981) Zeta potential in colloid science. Academic Press, New York

Janusz W (1994) Electrical double layer at the metal oxide/electrolyte interface in interfacial forces and fields: theory and applications. Surf Sci 85(4):135-206

Jayaramudu T, Ko H-U, Chan Kim H, Woong Kim J, Kim J (2019) Swelling behavior of polyacrylamide-cellulose nanocrystal hydrogels: swelling kinetics, temperature, and $\mathrm{pH}$ effects. Materials 12:2080

Journal of Laws of the Republic of Poland (2017) Warsaw, pos 2294

Kabata-Pendias A (2004) Soil-plant transfer of trace elements-an environmental issue. Geoderma 122:143-149

Kitahara Y, Okuyama K, Ozawa K, Suga T, Takahashi S, Fujii T (2012) Thermal decomposition of acrylamide from polyacrylamide. Time-resolved pyrolysis with ion-attachment mass spectrometry. J Therm Anal Calorim 110:423-429

Kumpiene J, Lagerkvist A, Maurice C (2007) Stabilization of Pb- and $\mathrm{Cu}$-contaminated soil using coal ash and peat. Environ Pollut 145:365-373

Lee BJ, Schlautma MA (2015) Effects of polymer molecular weight on adsorption and flocculation in aqueous kaolinite suspensions dosed with nonionic polyacrylamides. Water 7:5896-5909

Lentz RD, Shainberg I, Sojka RE, Carter DL (1992) Preventing irrigation furrow erosion with small applications of polymers. Soil Sci Soc Am J 56:1926-1932

Li N, Bai R, Liu C (2005) Enhanced and selective adsorption of mercury ions on chitosan beads grafted with polyacrylamide via surface-initiated atom transfer radical polymerization. Langmuir 21:11780-11787

Lu C, Pelton R (2001) PEO flocculation of polystyrene-core poly(vinylphenol)-shell latex: an example of ideal bridging. Langmuir 17:7770-7776

McBride MB (2003) Toxic metals in sewage sludge amended soil: has the promotion of beneficial use discounted the risks? Adv Environ Res 8:5-19

Moore GSM (1993) The $\alpha-\beta$ inversion in submilligram particles of natural quartz. J Therm Anal Calorim 40:115-120

Mothé GC, Ambrósio RMC (2007) Processes occurring during the sintering of porous ceramic materials by tg/dsc. J Therm Anal Calorim 87:819-822

Őnal M, Sarikaya Y (2007) Thermal behavior of bentonite. J Therm Anal Calorim 90:167-172

Ostolska I, Wiśniewska M (2015) Investigation of the colloidal $\mathrm{Cr}_{2} \mathrm{O}_{3}$ removal possibilities from aqueous solution using the ionic polyamino acid block copolymers. J Hazard Mater 290:69-77
Pan ZA, Campbell AP, Somasundaran P (2001) Polyacrylic acid adsorption and conformation in concentrated alumina suspensions. Colloid Surf A 191:71-78

Pelssers EGM, Cohen Stuart MA, Fleer GJ (1990) Kinetics of bridging flocculation. J Chem Soc Faraday Trans 86:1355-1361

Pueyo M, Lopez-Sanchez JF, Rauret G (2004) Assessment of $\mathrm{CaCl}_{2}$, $\mathrm{NaNO}_{3}$, and $\mathrm{NH}_{4} \mathrm{NO}_{3}$ extraction procedures for the study of $\mathrm{Cd}$ $\mathrm{Cu}, \mathrm{Pb}$ and $\mathrm{Zn}$ extractability in contaminated soils. Anal Chim Acta 504:217-225

Renault R, Sancey B, Badot PM, Crini G (2009) Chitosan for coagulation/flocculation processes - an eco-friendly approach. Eur Polym J 45:1337-1348

Siah Lee C, Robinson J, Fong Chong M (2014) A review on application of flocculants in wastewater treatment. Proc Saf Environ Prot 92:489-508

Singh G, Letey J, Hanson P, Osterli P, Spencer WF (1996) Soil erosion and pesticide transport from an irrigated field. J Environ Sci Health B 31:25-41

Sojka RE, Bjorneberg DL, Entry JA, Lentz RD, Orts WJ (2007) Polyacrylamide in agriculture and environmental land management. Adv Agron 92:75-162

Sternik D, Gładysz-Płaska A, Grabias E, Majdan M, Knauer W (2017) A thermal, sorptive and spectral study of HDTMAbentonite loaded with uranyl phosphate. J Therm Anal Calorim 129:1277-1289

Sternik D, Gładysz-Płaska A, Grabias E, Majdan M, Knauer W (2019a) Study of effect of phosphate and uranium ions on the thermal properties of surfactant-modified natural red clay using TGFTIR-MS techniques. J Therm Anal Calorim 136:425-439

Sternik D, Wiśniewska M, Nowicki P (2019b) Thermal degradation of peat-based activated carbons covered with mixed adsorption layers of PAA polymer and SDS surfactant. Thermochim Acta 676:71-83

Trout TJ (1996) Furrow irrigation erosion and sedimentation: onfield distribution. Trans ASAE 39(5):1717-1723. https://doi. org/10.13031/2013.27689

Uddin F (2008) Clays, nanoclays, and montmorillonite minerals. Metall Mater Trans A 39:2804-2814

Van Gestel CAM (2008) Physico-chemical and biological parameters determine metal bioavailability in soils. Sci Total Environ 406:385-394

Wiśniewska M, Chibowski S, Urban T (2015) Impact of polyacrylamide with different contents of carboxyl groups on the chromium (III) oxide adsorption properties in aqueous solution. J Hazard Mater 283:815-823

Wiśniewska M, Chibowski S, Urban T (2017) Comparison of adsorption affinity of ionic polyacrylamide for the surfaces of selected metal oxides. Adsorpt Sci Technol 35:582-591

Wiśniewska M, Fijałkowska G, Szewczuk-Karpisz K (2018) The mechanism of anionic polyacrylamide adsorption on the montmorillonite surface in the presence of $\mathrm{Cr}(\mathrm{VI})$ ions. Chemosphere 211:524-534

Wiśniewska M, Chibowski S, Urban T, Terpiłowski K (2019a) Investigations of chromium(III) oxide removal from the aqueous suspension using the mixed flocculant composed of anionic and cationic polyacrylamides. J Hazard Mater 368:378-385

Wiśniewska M, Fijałkowska G, Szewczuk-Karpisz K, Urban T, NosalWiercińska A, Wójcik G (2019b) Comparison of adsorption affinity of anionic and cationic polyacrylamides for montmorillonite surface in the presence of chromium(VI) ions. Adsorption 25:41-50

Yariv S, Cross H (2002) Organo-clay complexes and interactions. Marcel Dekker, New York

Zaman AA, Tsuchiya R, Moudgil BM (2002) Adsorption of a lowmolecular-weight polyacrylic acid on silica, alumina, and kaolin. J Colloid Interface Sci 256:73-78

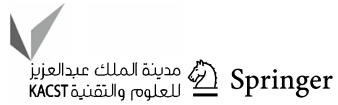


Zhao Y, Chen Y, Li M, Zhou S, Xue A, Xing W (2009) Adsorption of $\mathrm{Hg}^{2+}$ from aqueous solution onto polyacrylamide/attapulgite. $\mathrm{J}$ Hazard Mater 171:640-646

Zhou S, Xue A, Zhao Y, Wang O, Chen Y, Li M, Xing W (2011) Competitive adsorption of $\mathrm{Hg}^{2+}, \mathrm{Pb}^{2+}$ and $\mathrm{Co}^{2+}$ ions on polyacrylamide/attapulgite. Desalination 270:269-274
Publisher's Note Springer Nature remains neutral with regard to jurisdictional claims in published maps and institutional affiliations. 